\title{
The effect of adaptive performance support system on learning achievements of students
}

Citation for published version (APA):

Stoyanov, S., Kommers, P., Mileva, N., \& Martínez Mediano, C. (2008). The effect of adaptive performance support system on learning achievements of students. International Journal of Continuing Engineering Education and Lifelong Learning (IJCEELL), 18(3), 351-365. https://doi.org/10.1504/IJCEELL.2008.018837

\section{DOI:}

10.1504/IJCEELL.2008.018837

Document status and date:

Published: 01/06/2008

Document Version:

Peer reviewed version

Please check the document version of this publication:

- A submitted manuscript is the version of the article upon submission and before peer-review. There can be important differences between the submitted version and the official published version of record. People interested in the research are advised to contact the author for the final version of the publication, or visit the DOI to the publisher's website.

- The final author version and the galley proof are versions of the publication after peer review.

- The final published version features the final layout of the paper including the volume, issue and page numbers.

Link to publication

\section{General rights}

Copyright and moral rights for the publications made accessible in the public portal are retained by the authors and/or other copyright owners and it is a condition of accessing publications that users recognise and abide by the legal requirements associated with these rights.

- Users may download and print one copy of any publication from the public portal for the purpose of private study or research.

- You may not further distribute the material or use it for any profit-making activity or commercial gain

- You may freely distribute the URL identifying the publication in the public portal.

If the publication is distributed under the terms of Article 25fa of the Dutch Copyright Act, indicated by the "Taverne" license above, please follow below link for the End User Agreement:

https://www.ou.nl/taverne-agreement

Take down policy

If you believe that this document breaches copyright please contact us at:

pure-support@ou.nl

providing details and we will investigate your claim.

Downloaded from https://research.ou.nl/ on date: 26 Apr. 2023 
Running head: ADAPTIVE PERFORMANCE SUPPORT SYSTEM AND LEARNING

\title{
ACHIEVEMENTS
}

This is a pre-print of the article that was published as
Kommers, P., Stoyanov, S., Mileva, N., \& Martínez Mediano, K. (2008). The effect of adaptive performance support system on learning achievements of students. International Journal of Continuing Engineering Education and Lifelong Learning, 18 (3), 351-365.

International Journal of Continuing Engineering Education and Lifelong Learning is avalilable online at http://www.inderscience.com/browse/index.php?journalID=6\&year=2004\&vol=14\&issue $=4 / 5$

The effect of adaptive performance support system

on learning achievements of students

\author{
Slavi Stoyanov \\ Open University of The Netherlands \\ Piet Kommers \\ University of Twente, The Netherlands \\ Nevena Mileva \\ Plovdiv University, Bulgaria \\ Catalina Martínez Mediano \\ National University of Distance Education, Spain
}

Correspondence concerning this article should be addressed to Slavi Stoyanov, Open

University of the Netherlands, Educational Technology Expertise Centre, PO Box 2960, 6401

DL Heerlen, The Netherlands. E-mail: slavi.stoyanov@ou.nl 


\begin{abstract}
The study compares the effectiveness of two performance support systems, adaptive and non-adaptive, on learning achievements of engineering students. The research design, in addition, controls for a possible effect of learning style. The analysis reveals that students working with an adaptive performance support system score significantly higher than students using a non-adaptive performance system on a performance test across different learning styles. The only variation in the two experimental conditions, manipulated in the study, is embedded adaptive arrangement based on learning style. Embedded adaptation mode accommodates learning preferences of students through the structure of learning content as an association between types of learning content and different learning styles is assumed. Learning style does not produce a significant difference in the performance achievements of students and there is no indication for an interaction effect between performance supports system as a method of instruction and learning style. These results are explained by two theoretical positions introduced in the background of the study, namely coping behavior and the distinction between level and style type of cognitive constructs.
\end{abstract}

Keywords. Adaptive performance support system, learning style, embedded adaptation, treatment-by-learner traits interaction, treatment-by-learning outcomes interaction 


\section{The effect of adaptive performance support system on learning achievements of students}

\section{Introduction}

Instructional designers and curriculum developers in higher education have adopted from business and industry the idea of electronic performance support system to address in an effective and efficient way the requirements for performance oriented learning of students. Performance oriented learning is aimed at developing a set of competencies allowing adaptive behavior of students to deal successfully with either domain-specific problems or issues arising on the cross sections of different professional fields. The electronic performance support system movement was the needed catalyst to stimulate the efforts of higher education professionals to explore the effect of (a) practical measures for active learning and application of skills; (b) the role of recent technology development to address instructional issues; (c) filtering and adequate representation of learning resources; and (d) an integrative theoretical approach for conceptual operationalization of performance support.

The interest toward the concept of performance support system in higher education is growing, but the number of empirical studies investigating the effect of performance support on students' learning is limited. The first attempts, although not comprehensive in scope, are encouraging (Stoyanov and Kommers, in press; Stoyanov, Kommers, Bastieans \& Mediano, this issue). There are several conclusions that can be drown from the research on implementing the idea of performance support in higher education. The concept, as it was developed in business and industry, can not be automatically implemented in higher education on one-to-one basis. Performance support systems in business and industry target an increase in individual and organizational performance as learning is expected to occur as a side effect of performance. Considering learning as a secondary to performance concern contradicts the purpose of higher education. The concept of performance support system, needs an elaboration to adequately reflect the goals, expectations and requirements of higher education. A comprehensive operationalization of the concept of performance support in higher education is presented elsewhere (Stoyanov, Kommers, Bastieans and Mediano, this issue). Here only the most prominent characteristics of the concept are listed, namely: (a) defining a set of authentic problems including classes of easy-to-complex tasks, related to specific working environment; (b) changing the focus from the lower levels of learning taxonomy such as knowledge and understanding, towards its higher levels such as solving real-world problems; (c) creating opportunities for deliberate practicing of tasks; (d) gradually diminishing the amount of support (scaffolding); (e) providing variety of instructional stimuli (resources); (e) allowing constant access to learning resources, (f) giving formative performance feedback $(\mathrm{g})$ adapting performance support instruction to level of knowledge and learning style of students; and (h) using the most recent development of information and communication technologies (ICT) to design and develop software applications for performance support.

The experience that was built up in developing electronic performance support system suggested a particular component structure of the software applications interface to provide an effective functional support for performance. The interface framework, consisting of an advisory component, an information component and a training component is a necessary but not a sufficient condition for an effective performance. It is the structure of content and learning activities included in this framework that really makes the difference. 
This paper explores the possibility of performance systems for adaptive support with a special attention to learning style. The idea of adaptation is inherently implied in the shortest and probably the most popular definition of electronic performance support systems - just-intime, just-enough, and just-at-the-point need support for job performance. This definition, however, is too general to inform sufficiently on the characteristics of adaptive performance support system. What follows are some steps in the attempt to operationally define adaptive performance support. Four issues will be addressed: conceptual operationalization of learning style, adaptive instruction based on learning style, technological implementation of learning style adaptation, and implementation of the idea of adaptive performance support in the software application we have developed.

\subsection{Learning style adaptation in technology enhance learning}

The development of adaptive software applications for educational and training purposes has been dominated by instructional design solutions exploring level of knowledge as a single learner's characteristic determining effective individualization of learning (CorbalánPérez, Kester, and van Merriënboer, 2006; Merrill, 2002; Oughton \& Reed, 2000; Wisberg, 2003). Level of knowledge is a very strong factor to be taken into account when designing software applications for educational purposes. The performance support system DIPSEIL (Distributed Internet-Based Performance Support Environment for Individualised Learning) which we have developed, adapts to level of knowledge of students incorporating a special module for it, called Capability Advisor. In this study we are more interested in the instructional design solutions implemented in DIPSEIL, which are based on learning style. One reason, basically, is that level of knowledge, as a factor for adaptation, has been studied more extensively than learning style. Another reason, particularly, is that learning style is expected to play a more substantial role in performance support systems than in other types of software applications for educational purposes. The special requirement and technical arrangement for practicing may make performance support systems more appropriate for the learning styles of activist and pragmatist and less relevant for more reflective or more theoretically oriented learning styles.

Studies on adaptive software applications have indicated, that not only level of knowledge, but also learning style is important source of individual variation and a moderator of the effect of instruction on learning achievements (Brown, Cristea, Stewart, and Brailsford, 2005; Merrill, 2002; Papanikolaou, Grigoriadou, Kornilakis, and Magoulas, 2001). Research on learning style for adaptive instruction has a long tradition (see Jonassen and Grabowski, 1993; Riding and Reiner, 1997), but it has produced some inconsistent findings (Ayersman and von Minden, 1995; Kirton, 2003; Martinsen and Kaufmann, 1999; Meneely and Portillo, 2005; Oughton and Reed, 2000; Stoyanov and Kirschner, 2007; Stoyanov and Kommers, in press,), which need explanation in order to inform the design and development of adaptive software applications. There are two groups of reasons that can account for this inconsistency. The first one is related to the definition and conceptual operationalization of learning style as a cognitive construct. The second one is related to the definition and theoretical background of adaptive instruction.

\subsection{Conceptual operationalization of learning style}

The contemporary theory of learning style defines this construct as a stable pattern of individual cognitive functions and traits that determines the preferred way of approaching instructional stimuli. There are several empirically validated assumptions based on this definition. (Kirton, 2003). 
A distinction should be made between style class cognitive constructs (in what way) and level (how much) classes (inherent or learned). Some examples of level types of constructs are abilities, knowledge, and competence. Learning style is conceptually independent to level constructs. Level and style measures, if pure, correlate not at all. Different learning styles can operate on the same level of expertise and the same level of competence may be distributed across different learning styles. Some instructional situations could however favor a particular style more than another.

Style and behavior could not necessary be in accord, or put it in another way, a 'cognitive gap' between preferred behavior and observable behavior could exist. People may happen to behave outside their prefer way of doing, a situation in which they apply the cognitive mechanism of coping behavior. They could be convinced or forced to learn in way that is different from their learning style, as this way is considered to be more effective and/or socially desirable. Learning strategy followed for some purposes does not necessary conform to a learner's preferred way of learning.

The flexibility of learning requires to learn not only learning strategies that are consonant with a preferred style, but also to learn to shift to less congenial learning styles, that are more effective in a particular situation.

A learning strategy, method or technique, can be learn to increase level of performance directly, or make more effective use of the available style as stimulating its strengths and compensating for its weakness.

\subsection{Adaptive instruction based on learning style}

Adaptation has been associated with a purposeful effort for accommodating individual differences in learner characteristics for designing effective instruction (Jonasssen and Grabowski, 1993). Several instructional design adaptive models to accommodate learning style have been developed. Preferential adaptation implies that the instructional decisions take the strengths of a particular learning style into account (Jonassen and Grabowski 1993; Stoyanov and Kommers, in press). Compensation adaptation means that the decision making takes the weaknesses of a particular style into account to compensate for them (Clark, 1983; Jonassen and Grabowski,1993; Salomon, 1979).

Preferential and compensational adaptation can be based on pre-assessment adaptive mode (Jonassen and Grabowski, 1993; Leutner and Plass, 1998, Stoyanov and Kommers, in press; Valley 1995) or on embedded adaptive mode (Stoyanov and Kommers, in press; Valley 1995). Pre-assessment adaptation specifies learning paths of learners on the basis of filling out some instruments such as check-lists, tests, inventories, or questionnaires. Embedded adaptation accommodates learning styles through a particular way of structuring learning content. For example, information can be structured as background information, examples, procedures and a requirement for practice. Learners' preferences can be implicitly identified through the choice and order of selecting these types of instructional stimuli.

In addition to attempts for accommodating individual differences in learners' traits, instructional solutions have to reflect the differences in learning outcomes and goals of instruction. Learning outcomes have been considered as the most important determinant of instructional-design decision making (Gané, 1985; Jonassen, 2004; Merrill, 2002; Reigeluth and Stein, 1983; Van Merriënboer and Kirschner, 2007). Different learning outcomes activate different cognitive processes, which then should be supported by appropriate instructionaldesign arrangements. The definition of adaptation that guides the design of effective, efficient and appealing instructional design solutions should therefore include both theoretical positions: adapting to learner (treatment-by-learner traits interaction) and adapting to instruction (treatment-by-learning outcomes interaction). Each of these two theoretical perspectives, taken separately, is a necessary but not a sufficient condition to reflect the 
complexity of adaptation. For a long time they have been considered as confronting 'neitheror' extremes. There are some indications, however, that this situation is changing. Merrill (2002) introduced the 'learning style-by-strategy interaction'. He believed, however, that it was secondary to 'content-by-strategy interaction', as learning style could not make a difference in the essential elements of instructional strategy. Some studies included individual differences in level of expertise and mental efforts as factors for task selection within an instructional strategy for complex learning (Corbalán-Pérez, Kester, and Van Merriënboer, 2006). The studies on learning style-by-strategy and level of expertise-by-strategy have emphasized on level type cognitive constructs. Merrill (2002) provided examples with potential level constructs (intelligence and cognitive complexity). Corbalán-Pérez, Kester, and Van Merriënboer (2006) investigated the role of manifested level (knowledge and skills).

In the project we are reporting on, the DIPSEIL performance support system is the instructional approach (treatment-by-learning outcomes interaction) which learners should adapt to because it is considered as the most effective and efficient way in which the goal of instruction can be reached. The instructional approach implemented in this performance support system should at the same time adapt to learning preferences of students (treatmentby-learner traits interaction), as the performance oriented instructional approach should also be perceived by students as appealing one.

The DIPSEIL adaptive performance system is aimed at supporting students to build a learning strategy that is oriented toward solving different classes of either well-defined or illstructured problems and the approach accommodates, through this process, the learning style of students as it enhances the strengths of a particular style, and compensates for its weakness. The learning resources are designed to support basically the dominant learning preference, but they offer support for the non-preferred style as well.

The effectiveness of technological solutions on adaptive instructional approaches accommodating learning style depends on the extent to which the architecture, functionality, and the interface of software applications reflect adequately the findings produced in the learning style paradigm.

\subsection{Technological implementations of adaptive approaches on learning styles}

Probably the most productive paradigms in which many projects in developing adaptive educational applications have been realized are Intelligent Tutoring Systems, Adaptive Educational Hypermedia, and Adaptive Educational Web-Based Systems. Although using different names, they belong to one paradigm as far as they are built upon a common conceptual background that includes domain knowledge, expert model, student model, pedagogical model, and communication model. The systems that have been developed within the theoretical framework of Intelligent Educational Systems made considerable progress in refining the properties of user models and promoting more advanced instructional techniques, but there are still some flows related to the definition of adaptation and operationalization of learning style that reduce the effectiveness of the technological solutions applied.

In some applications no distinction is made between knowledge, which is a level type of cognitive construct, and learning style, which is a preference type of cognitive construct (Brown, Cristea, Stewart, and Brailsford, 2005). In other attempts, no difference is made between learning style and instructional strategy (Gilber and Han, 1999). Most of the systems implemented measurement instruments that had low validity and reliability indicators (see for example Brown et al., 2005; Papanikolaou, Grigoriadou, Kornilakis, and Magoulas, 2001). In some Adaptive Educational Hypermedia (AEH) projects an attempt is made to match the instructional strategy to the defined learner model, but it is not always explicitly stated which instructional strategy is used (Brown et al., 2005). When an instructional approach is defined explicitly, it does not reflect the current trends in modern instructional design theory and 
practice (Papanicolaou et al., 2001). Another issue found is that the discussion on design approaches based on learning styles has been replace by discussion on learning style classifications (Brown at al, 2005). When a design approach for adaptation is explicitly referred to, it is only preferential type of adaptation based on pre-assessment mode (Papanicolaou et al., 2001). A common issue with AEH systems is that the evaluation of these systems has been hardly discussed. If evaluation was conducted, it was not based on a strong research design (Brown et al., 2005; Papanicolaou et al., 2001).

The issues related to designing adaptive software applications for educational purposes (performance support system is a such application) can be summarised in the following statements:

1. The challenges of designing adaptive software applications for educational purposes are conceptual rather than technological.

2. Technological solutions do not reflect recent development of instructional design for adaptive learning.

3. Adaptive instructional approaches based on level types of cognitive constructs such as abilities, knowledge, competence, and expertise still dominate research on designing adaptive software applications. The number of studies based on learning style is still limited.

4. Conceptual design of adaptive software applications for educational purposes does not make a clear distinction between knowledge, learning style and instructional approach.

5. Adaptive software applications do not operationalise the both sides of the definition of adaptation: (a) adaptation of instruction to learners and (b) adaptation of learners to instruction.

6. Adaptive technological applications implement more often preferential matching adaptation model.

7. Adaptive software application apply more often pre-assessment adaptive mode, while the attempts for embedded learning adaptation are very few.

8. The effectiveness of the implementation of the idea of learning style adaptation in a performance support system is not affected directly by the component interface structure consisting of advisory component, an information component and a training component, but rather by the structure of the content and learning activities .

9. Evaluation of the effectiveness of adaptive software applications in most of the cases does not apply powerful research designs.

10. The research design in the evaluation of performance support system in education do not control for possible effect of learning style as it is expected that performance systems might better support some of the learning style, namely activist and pragmatist.

The operationalization of performance support system, as it was shortly discussed in the Introduction section, identifies the learning outcomes of this instructional approach, thus contributing to adapting students to the requirements of instruction It is of crucial importance, for either conceptual or technological design of performance support system, to adequately and comprehensively define the attribute 'adaptive' of the concept adaptive performance support system.. The next step is to clarify what does 'adaptive' in the performance support mean and what does it imply for this instructional approach implemented in software applications supporting performance. This could be a contribution to adapting instruction to learners. 


\subsection{The idea of adaptation as implemented in the DIPSEIL performance support system}

The definition of performance support system implies the idea of embedded adaptation through accommodating learning style within the structure of content and learning activities, rather than applying pre-assessment mode of adaptation. The DIPSEIL performance support system structures learning content into the following categories: background information (definitions, theoretical models and frameworks), examples (work-out examples, demonstrations, simulations), procedures (step-by-step approaches, techniques, instruments,). The system requires deliberate practicing of learning tasks. Being involved in performing learning tasks, a student can select at any moment of need any of the supportive instructional stimuli as listed above (background information, examples, procedures). Learners do not have preferences to all instructional stimuli offered by the system but in order to develop a versatile learning strategy students are also suggested to use instructional resources, which they probably would not pick up. For some instructional stimuli, learners have to apply the cognitive mechanism of copying behaviour, that is behaviour which does not correspond to their inner learning preferences. Learners define their learning preferences not by filling out in advance a learning style questionnaire, test or check list, but by selecting types and order of learning content.

The question however is how types of learning content are related to types of learning style? What is the learning style of a learner who selects first, for example, background information? The relationship between types of learning style and types of learning content can be conceptualized through Honey and Mumford learning style theory (Honey and Mumford, 1992). The theory is an instrumental elaboration on Kolb's Experiential Learning theory. Retaining Kolbs's theory intact, Honey and Mumford developed a measurement instrument that is considered as a more valid and reliable operationalization of this theory than the original Kolb's Learning Style Inventory (LSI, Kolb, 1976; Kolb, 1884; Smith and Kolb, 1986). Honey and Mumford define learning style according to stages of the general learning cycle (actually it is a spiral, continuous iterative process). The stages are (a) having experience, (b) reviewing experience, (c) concluding from experience, and (d) planning the next step. People can start anywhere on the cycle but they develop preference to some of them at the expense of other. The stages are mutually amplifying each other as none of them is fully effective but every one is an indispensable part of the whole process. The four learning style according to Honey and Mumford are Activist, Reflector, Theorist, and Pragmatist. Each of them can be associated to one of the stages of the general learning cycle: activist to experiencing stage, reflector to reviewing, theorist to concluding, and pragmatist to planning. Following the description of learning styles we assume that each of them has preference to one of learning content types: activist to involvement in learning tasks; reflector to studying work-out examples and observing demonstrations, and stimulations; theorist to exploring theoretical rationales and models; pragmatist to applying step-by-approach or procedures to performing the tasks. Successful performing of learning tasks requires studying all types of supportive learning content as learning preference determines which of the instructional stimuli will be approached first, and what the sequence of approaching learning content types will be.

This study aims to test the effectiveness of performance support adaptive instructional arrangements exploring the following research questions: What is the effect of adaptive performance support system on learning achievements of students? And Is the effect of performance support system different for learning styles? We have made two assumptions based on the theoretical rational of the study: (a) working with the adaptive performance support system (DIPSEIL) will result in a better performance compared to non-adaptive 
performance support system (IPSS-EE); and (b) the adaptive performance support system (DIPSEIL) will improve the performance of students across all learning style.

Next section introduces to the components of the research design arranged to explore the research questions and to check the assumptions.

\section{Method}

The study applies a factorial experimental design with post-test measurement. One of independent variables is performance support instructional approach with two levels adaptive performance support system and non-adaptive performance support system. The adaptive performance support system, DIPSEIL, includes all features of a typical performance support system for educational purposes as they were discussed in the introduction section of the study (see also Stoyanov, Kommers, Bastieans and Mediano, this issue), but also adaptive arrangements that were described in the previous section. The non-adaptive performance support system, called IPSS-EE (Internet-Based Performance Support System with Educational Element), contains the feature of a typical performance support system for educational purposes but without adaptive arrangements. The second independent variable is learning style with four levels - activist, reflector, theorist and pragmatist (Honey and Mumford, 1992).

The dependent variable of the study is learning achievements of students, measured by a performance test.

\subsection{Participants and procedure}

The participants in this study were 46 first-year university students following the course Informatics for Physics Engineers. They were randomly assigned to the experimental and control groups. The experimental group worked with DIPSEIL system and the control group used IPSS-EE system in studying one course's module which prolonged about a month. During this period the students conducted a performance test. They were told that the results would not affect the final grade as the scores will only be used for research purposes. Before the experiment all students fill out Honey and Mumford Learning Style Questionnaire to identify their learning style.

\subsection{Instruments}

Two measurement instruments were used in this study: a performance test and a learning style questionnaire. The performance test contained 5 performance items to measure the level of skills acquisition. Skill acquisition means not only proficiency in performing practical learning tasks, but also transfer of learning to new situations as an evidence for the extent to which the students have understood the principles underlying skills. The scores follow a national assessment system according to which 6 is the highest score; 2 is the lowest score; 3 is the pass/not pass threshold.

The Learning Style Questionnaire (Honey and Mumford, 1992) consists of 80 statements (20 indicative for each of the four learning styles). People are asked to identify the extent to which they agree with the items, ticking each statement which they are agree with and crossing those that they disagree with. Here are some examples of statements indicative for the four learning style: activist learning style - "I actively seek out new experiences."; reflector - "I listen to other people point of view before putting my own forward "; theorist "I regularly question people about their basic assumption"; pragmatist - "What matters most is whether something works in practice." People are told that there are not right and wrong answers as they are encouraged to answer to all items. Typically the questionnaire should be filled out between 10-15 minutes. The raw scores on each learning style are compared to norms to identify 5 bands of scores: (a) very strong preferences (the point at which $10 \%$ of the scores are above and $90 \%$ are below); (b) scores in this band indicate strong, but not very 
strong preference (the point at which $30 \%$ of the scores are above and $70 \%$ are below; (c) scores in this band indicate moderate preference (the middle $40 \%$ of the scores, with $20 \%$ above and $20 \%$ below the mean; (d) scores indicate low preferences (the point at which $70 \%$ of the scores are above and $30 \%$ are below; and (e) very low preferences (the point at which $10 \%$ are bellow and $90 \%$ are above). The questionnaire has established both general norms based on 3500 subjects, and norms for different occupational groups. Although the specific norms are more sensitive to identify learning style, in this study we use the general norms because the participants are first year students and no of the specific norms are close to them. Test-retest reliability measure of the questionnaire applying Pearson's product-moment coefficient of correlation is quite satisfactory (.89).

\section{Analysis}

The value of Levene test for homogeneity of variance $(F=1.6, p=18)$ indicated no violence of the assumption that the variability of score for each of the groups is similar. The analysis confirmed the assumption that that engineering students using the adaptive performance support system DIPSEIL performed significantly better than students using the non-adaptive performance support system IPSS-EE. The results indicated a significant main effect of the instructional method on the performance achievements of students with a large effect size, $F(1,38)=7.7, p=.009$, partial eta squared was .17 . Table 1 presents the mean figures of both groups and learning styles.

Table 1. Mean figures of learning style and groups

\begin{tabular}{llll}
\hline Group & Learning style & Mean & Std.Deviation \\
\hline Adaptive & Activist & 5.4 & .3 \\
& Reflector & 5.7 & .4 \\
& Theorist & 5.4 & .4 \\
& Pragmatist & 5.4 & .4 \\
& Total & 5.5 & .7 \\
\hline Non-Adaptive & Activist & 4.9 & .3 \\
& Reflector & 4.6 & .4 \\
& Theorist & 4.6 & .4 \\
& Pragmatist & 4.8 & .4 \\
& Total & 4.7 & .9 \\
\hline
\end{tabular}

Note. $\mathrm{N}=46$; Dependent variable is performance of students

The analysis revealed a non-significant main effect of learning style on performance achievements of students, $[\mathrm{F}(38,3)=.056], \mathrm{p}=.98$, eta squared .004 . No significant statistical difference was found on the interaction effect between method of instruction and learning style, $[\mathrm{F}(38,3)=.9], \mathrm{p}=.015$, eta squared, .015 . Figure 1 visualises the results of the interaction effect between instructional method and learning style. It seems that nonadaptive performance support system favours a little bit activist and pragmatist than reflector and theorist learning style. Activist, theorist and pragmatist learning style perform equally well in adaptive performance support condition. Reflector learning style benefited the most from the adaptive performance support system. As the figure shows, the margin of improvement for reflectors is bigger than for other learning styles. The results related to the effect of learning style and the interaction effect between learning style and instructional method affirmed the assumption that the adaptive performance support system, DIPSEIL, was 
equally effective across the four learning style. Learning style did not affect the achievements of students, who used performance support systems, either adaptive or non-adaptive.

Figure 1. Interaction of groups and learning styles

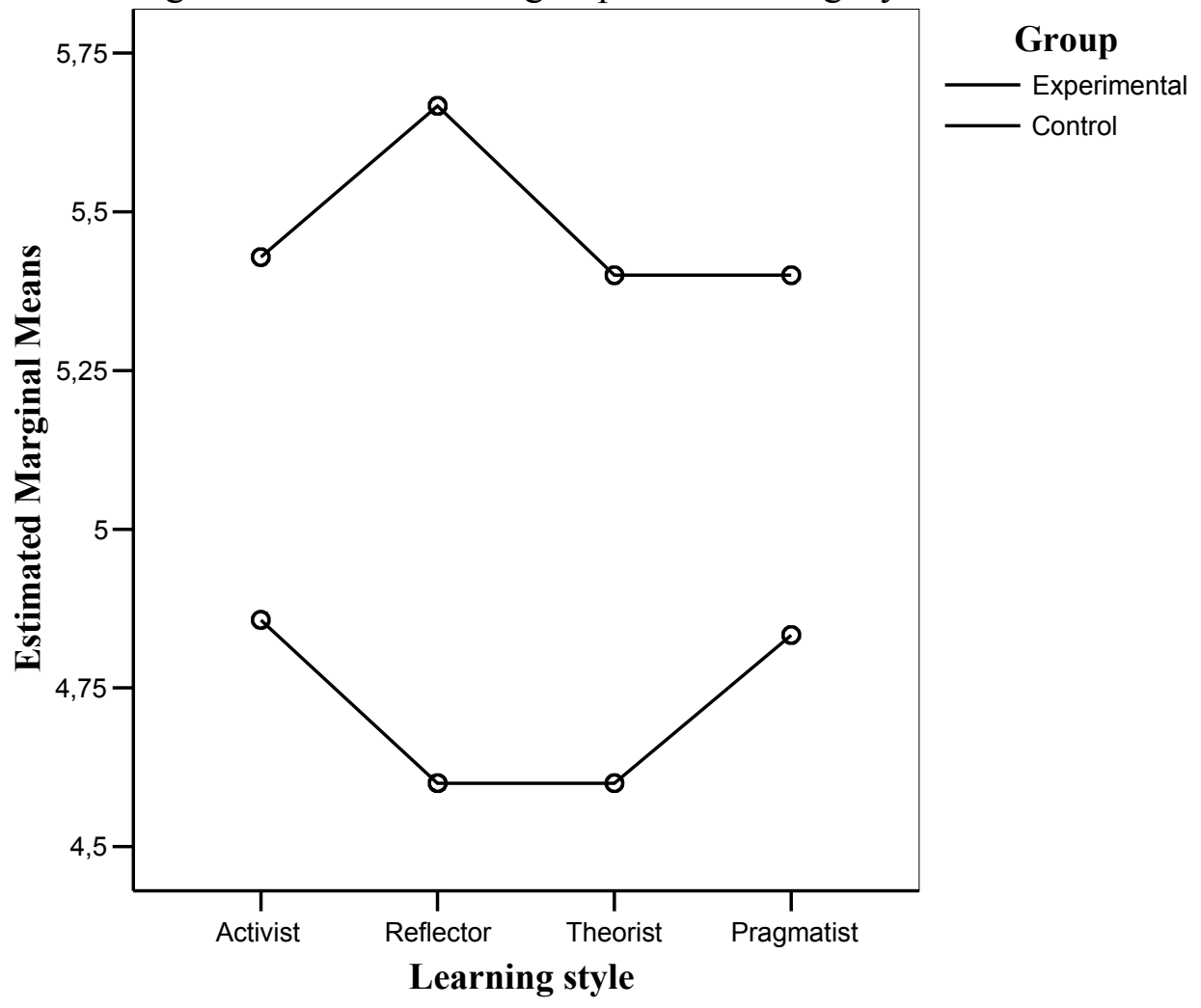

\section{Discussion}

The study investigated the effectiveness of performance support system adapting to learning style of students. Learning style was conceptually defined according to the principles of experiential learning theory (Kolb, 1984; Honey and Mumford, 1992). The main idea underlying the instructional design solutions is embedded adaptation which serves either preferential or compensation match of instruction to learners preferences. Embedded adaptation appears to be the most natural solution for performance support systems. This type of adaptation means that learning styles of students are accommodated through the structure of learning content as a particular learning style is associated with a particular type of learning content. Learners can initially pick up any of the available type of learning content. To ensure the building of a versatile learning style, learners are also advised to make a combination of all types of learning content as they are free to determine the order of selection. If a student, for example, expresses a preference first for background information and then a preference for examples, she or he is suggested to explore procedures as well. It is highly plausible that the higher performance results of students working with the adaptive performance support system are due to the embedded adaptation instructional arrangements. These arrangements were the only variations in the instructional conditions. Embedded adaptation does seem to be a 
popular direction of instructional design thinking, but the results of this study increase our optimism that it could be an effective and efficient solution. This is an adaptation by affordance, which implicitly suggests particular actions, rather than adaptation requiring first filling out some measurement instruments and then based on the outcomes, some explicit suggestions are made. At least it save time, but more important, students have a direct and imminent contact with the adaptive content as far as the adaptation is embedded into the learning content structure. Learners are not distracted with activities, which they sometimes perceive as redundant, before interacting with the content. Another issue with adaptation based on pre-assessment is that learners not always are convinced that suggestions made by the system match their preferences. The idea of embedded adaptation is a conceptual tool for understanding, but also for practically resolving the paradox of learning adaptation: adaptation means both adapting of instruction to learners but also adapting of learners to instruction. The key factor is learning content. Learning content contains what is necessary to be learn but also its structure creates opportunities for matching learners preferences. The structure of learning content implicitly serves both learning outcomes and learning preferences, hence learning styles.

Learning adaptation, either embedded or pre-assessment poses some challenges from instructional design point of view. The crucial one is determining the association between types of learning content and learning styles. In pre-assessment adaptation, any suggestion of the system should be based upon the assumption for a relationship between learning style, as defined by measurement instrument, and learning content ("if a student is identified as reflector learning style, then provide him/her with X type learning content"). In this study we provided an interpretation of this association, which was implemented in the interface of the adaptive performance support system. If someone would like to repeat the research in this study developing an adaptive performance support system, we suggest checking again this interpretation with a careful examination of the description of the four learning styles, before defining the set of associations between types of learning content and learning styles.

The embedded adaptation implemented in the adaptive performance support system was equally effective for all learning style. These arrangements created opportunity for students to make any combination of the components of learning content structure that matches best the individual preferences of students. The rule is simple: given a task to perform start with any of the type of supporting information you want, but do not overlook any of the other content types. The 'select-first' part of the rule serves preferential matching, while 'do not overlook' part serves the compensation matching adaptation. The lack of significant differences in the performance of students can be explained by cognitive mechanism of coping behavior. This is a type of behavior that is different from preferred behavior. When people are asked to behave in a way that is different from the their preferred one, they switch on coping behavior. People are capable of performing well even in non-preferred mode of behavior, because of the effect of this cognitive construct. When the reason for coping behavior disappears, people quick return to their preferred way of doing. On the negative side, coping behavior always requires more time, effort and energy. It is psychologically "expensive". The current study did not check for this effect. Another reason that can account for the lack of significant difference due to learning style is the evidence based position that style and level type of cognitive constructs are not related. A style is not better than another, they are just different. This is the instructional method (adaptive performance support system) that yields significantly better results and this is valid for all learning styles.

The adaptive performance support system was slightly more beneficial for reflectors than to activists, theorists and pragmatists. The reason is that to adequately reflect the need of first-year students and to prevent the risk from cognitive overload, the structure of learning 
content offered more work-out examples. Real-world case was presented, but as the context of work-out examples.

\section{Conclusions}

The results of this study could have several implications for the instructional design theory and practice.

Technological development of adaptive software applications based on learning style should reflect the developments in the contemporary learning style paradigm and the theories of adaptive instruction.

Learning adaptation has two sides: adapting instruction to learners and adapting learners to instruction. This position should be adequately operationalized in adaptive software applications for educational purposes.

Adaptive software applications should implement both preferential and compensational modes of adaptation.

Embedded adaptation is an effective and efficient way for improving performance of learners. Embedded adaptation means that learning preferences are accommodated through learning content structure where a type of learning content is associated with a learning style. Embedded adaptation is a natural way of practically resolving (a) the contradiction between adapting to instruction vs adapting to learners; and (b) the issue of preferential vs compensational modes of adaptation. Embedded adaptation serves equally well all learning styles.

\section{References}

Ayersman, D. and von Minden, A. (1995) 'Individual differences, computers and instruction', Computers in Human Behaviour, Vol. 11, Nos. 3-4, pp.371-390.

Brown, E. Cristea, A. Stewart, C. and Brailsford, T. (2005) 'Patterns in authoring of adaptive educational hypermedia: a taxonomy of learning styles', Educational Technology \& Society, Vol. 8, No3, pp. 77-90.

Clark, R. (1983) 'Reconsidering research on learning from media', Review of Educational Research, Vol. 53, pp.445-459.

Corbalan, G. Kester L., and Van Merriënboer J. J. G. (2006) 'Towards a personalized task selection model with shared instructional control', Instructional Science, Vol. 34 No 5, pp. 399-422.

Gagné, R. M. (1985) 'The conditions of learning and theory of instruction'. $4^{\text {th }}$ edition. NY: Holt, Rinehart and Winston.

Gilbert, J. andHan, C. (1999) 'Adapting instruction in searching of a 'significant difference', Journal of Network and Computer Applications, Vol. 22, pp. 149-160.

Honey, P. and Mumford, A. (1992) 'The Manual of learning styles'. Maidenhead, Berkshire: Published and Distributed by Peter Honey.

Jonassen, D. and Grabowski, B. (1993) 'Handbook of individual differences, learning and instruction. Hillsdale, NJ: LEA.

Jonassen, D. (2004) 'Learning to solve problems. An Instructional design guide'. San Francisco, CA: Pffeifer.

Kirton, M. (2003) 'Adaption - Innovation in the context of diversity and change'. London: Routledge.

Kolb, D. (1976) 'Learning style inventory; technical manual'. Englewood Cliffs, New York: Prentice-Hall. 
Kolb, D. (1984) Experiential Learning. Experience as a source of learning and development'. Englewood Cliffs, New York: Prentice-Hall.

Leutner, D. and Plaas, J. (1998) 'Measuring learning styles with questionnaires versus direct observation of preferential choice behavior in authentic learning situations: the visualiser/verbaliser behavior observation scale (VV-BOS)', Computers in Human Behavior, Vol.14, No. 4, pp. 543-557.

Martinsen, O. and Kaufmann, G. (1999) 'Cognitive style and creativity', in M. Runco and S. Pritsker (Eds.) Encyclopedia of creativity, V. 1. New York: Academic Press, pp. 273282.

Meneely, J. and Portillo M. (2005) 'The adaptable mind in design: relating personality, cognitive style, and creative performance', Creativity Research Journal, Vol. 8, pp. 291-298.

Merrill, M. D. (2002) 'Instructional strategies and learning styles: Which takes precedence?', in R.A. Reiser, and J.V. Dempsey (Eds.) Trends and issues in instructional technology. Columbus, OH: Prentice Hall, pp. 99-106.

Messick, S. (1984) 'The nature of cognitive style: problems and promise in educational practice', Educational Psychologist, Vol. pp.19, 59-74.

Oughton, J. M. and Reed, W. M. (2000) 'The effect of hypermedia knowledge and learning styles on student-centered concept maps about hypermedia', Journal of research on computing in education, Vol. 32, No 3, pp. $366-383$.

Papanikolaou, K. Grigoriadou, M. Kornilakis, H. and Magoulas G. (2001) 'Personalizing the interaction in a web-based educational hypermedia system: the case of ISPIRE', Retrieved May 17, 2004 from http://www.dcs.bbk.ac.uk/ gmagoulas/UM2001.pdf

Reigeluth C. M. and Stein F.S. (1983). 'The elaboration theory of instruction', in C.M. Reigeluth (Ed.) Instructional-design theories and models. Hillsdale, NJ: Erlbaum, pp. $335-82$.

Riding, R. and Reiner, S. (1997) 'Toward categorization of cognitive styles and learning styles', An International Journal of Experimental Educational Psychology (Double special issue), V. 17, Nos 1 and 2 (March and June), 1997, pp.5-27.

Salomon, G. (1979) 'Interaction of media, cognition and learning'. Mahwah, NJ: LEA. Smith, D. and Kolb, D. (1986) 'Manual of Learning Style Inventory (LSI-II)'. Cambridge.

Stoyanov, S. and Kirschner P. (2004) 'Expert concept mapping method for defining the characteristics of adaptive e-learning: Alfanet project case', Educational technology research and development, Vol.52, No 2, pp. 41-56.

Stoyanov, S. and Kirschner P. (2007) 'Effect of problem solving support and cognitive styles on idea generation: Implications for technology-enhanced learning', Journal of Research on Technology in Education, Vol. 40, No 1, pp. 77-85.

Stoyanov, S. and Kommers P. (2006). 'WWW-intensive concept mapping for metacognition in solving ill-structured problems', International Journal of Continuing Engineering Education and Lifelong Learning, Vol. 16, pp. 297315.

Stoyanov, S. and Kommers, P. (in press) 'Concept mapping instrumental support for problem solving' International Journal of Continuing Engineering Education and Lifelong Learning.

Valley, K. (1995) 'Learning styles and courseware design', Advance Learning Technology Journal (ALT-J), V. 5, No 2, pp. 43-51.

Van Merriënboer, J. Clark, R. and de Croock, M. (2002) 'Blueprints for complex learning: the 4C/ID model', Educational Technology, Research \& Development, Vol. 50, No 2, pp. 39-64. 
Van Merriënboer J. and Kirscher P.(2007) 'Ten Steps to Complex Learning: A Systematic Approach to Four-Component Instructional Design'. Mahwah, New Jersey: Lawrence, Erlbaum Associates.

Weisberg, R. (2003) 'Creativity and knowledge', in J. Davidson and R. Sternberg (Eds.) The Psychology of problem solving. New York: Cambridge University Press, pp.226-250. 